\title{
Development of Production Control in Small Batch Production
}

\author{
Péter Németh ${ }^{1}$ and Thomas Bernhard Ladinig ${ }^{2}$ \\ ${ }^{1}$ Széchenyi István University, Department of Logistics and Forwarding, 9030 Györ, Hungary \\ ${ }^{2}$ Széchenyi István University, Doctoral School of Regional Economics and Business Administration, 9030 Györ, Hungary
}

\begin{abstract}
Our aim with this paper is to develop a new performance measurement and control system for small batch production in the automotive industry. For this reason, we present our previous research results for warehouse performance measurement and adopt its methodology to production control. The proposed method is based on artificial intelligence (neural networks).
\end{abstract}

\section{Introduction}

Stable and predictable production systems are the foundation of profitable and sustainable operations in manufacturing. The external and internal factors of production are constantly hindering these factors. Our aim with this paper is to show the possibility of a new production control and performance management system based on artificial intelligence. First, we examined some earlier research of the Department than a possible solution will be presented for managing production control.

\section{Small batch production overview}

The small volume production business unit of the automotive OEM has a diverse product mix and many machine set-ups for different production orders that take only 4-12 hours on average to complete. Quality issues arise caused by the many machine set-ups and various products, which results in unstable processes and high variability, as well as complexity. The business unit is an extended workbench and tier-1 supplier, which is focusing on increasing efficiency and productivity within a functional job-shop manufacturing layout with timephased MRP planning and a multi-level dependent demand system.

The production system consists of three departments that contain all production processes from metal disc to final assembly of all the main products like doors, side panels, roofs, bonnets and hatches for premium small volume sports cars. The first department is the component production where metal components are pressed and laser cut out of aluminum or stainless steel discs that enter the facility pre-cut by a supplier. The second department contains all the assembly processes where the final assemblies are put together out of two to four main components and several smaller purchased parts like reinforcement parts to increase the stability of the products. The third and final department is called "finish" and it is responsible to ensure proper quality in terms of surface quality (which can be impacted by difficult pressing processes) and dimension (which is mostly influenced by the different mating technologies used at the assembly department). At the end the final products are ready to be shipped to the main body shop and subsequently the paint shop of several internal customers of the production system. Furthermore, there is one more department within the small volume job-shop segment which is the project and process management department, responsible for launching new customer projects on time and to ensure continuous smooth operations of all running projects throughout their life cycle.

In addition to the small-series job shop the business unit contains four other, more or less separated segments which are: quality department, logistics, fixture construction and robotics (development and construction of the fixtures, manufacturing cells and robot programs for the assembly department and other customers), tool making (development and construction of pressing tools for the component production and other customers). The high degree of vertical integration makes it difficult to create an adequate value stream and material flow because processes with very different batch sizes and processing times must be tied together efficiently. Compared to normal production series the production system would be divided into two separate segments, one being the pressing plant and the other would be the body shop where relatively high amounts of WIP inventory are quite common. Therefore, it is necessary to have large amounts of inventory to balance the differences in processing time and batch size. Also asset utilization for integration of new projects into existing production assets is quite common, so not all the available time can be used continuously for series production, but also periodical time frames must be planned as implementation time. 


\section{Proposed method for performance measurement}

Based on the previous research activity of the Department the most viable solution for designing a performance measurement system was the artificial neural network.

The main reason behind that is that the tool to be chosen should be able to predict the strategic level result based on operational level inputs. The operational level inputs can be "manipulated" in short term (for example not allowing overtime for the workers) but strategic level outcomes must be accepted and altering them in short term is not possible.

\subsection{Artificial neural network}

An artificial neural network (ANN) is a mathematical model that is inspired by the structure and functional aspects of biological neural networks. A neural network consists of an interconnected group of artificial neurons, and it processes information using a connectionist approach to computation. In most cases an ANN is an adaptive system that changes its structure based on external or internal information that flows through the network during the learning phase. This learning phase is important for the use of the model. With enough data from the past the ANN is able to learn the connection between the input and output data. Parallel with the learning phase a test phase is taking place where the network is testing itself with other data from the same problem. As a result, after the learning the ANN can be used to predict outputs data from input data.

Lots of different types of artificial neural networks are proposed in the literature [7], [14]. In our application we use Multi-layer Perceptron (MLP) which is one of the most widely known types of ANNs. The topological structure of the MLP type neural network is illustrated in Fig. 1.

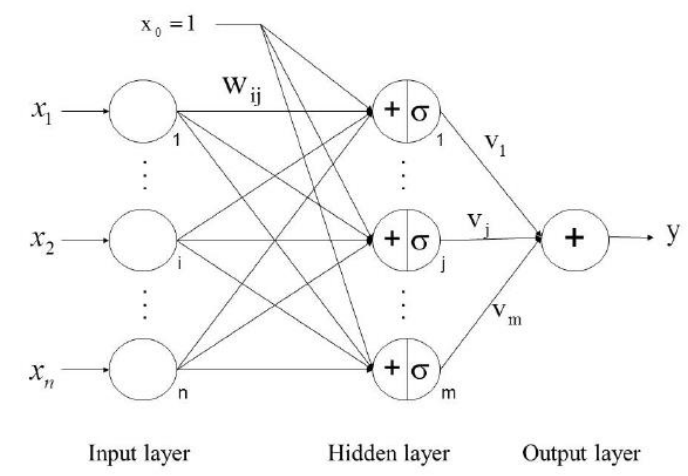

Figure 1. Topological structure of artificial neural network (MLP).

The network contains three layers. The input layer contains the inputs $\mathrm{xi}$. In the hidden layer $\mathrm{m}$ hidden neurons are applied. Between the input and hidden layers there are connection weights wij connecting the $\mathrm{i}$-th input and $\mathrm{j}$-th hidden neuron.

There is also a bias input $\mathrm{x} 0=1$ with weight $\mathrm{w} 0 \mathrm{j}$ to the $\mathrm{j}$-th hidden neuron. There is an output layer with output $y$. Between the hidden and output layers there are weights vj connecting the $\mathrm{j}$-th hidden neuron with the output.

The output of the neural network can be computed as:

$$
y=\sum_{j=1}^{m} v_{j} \cdot \sigma\left(\sum_{i=0}^{n} x_{i} \cdot w_{i j}\right)
$$

In Equation (1) $s$ is the sigmoid function:

$$
\sigma(s)=\frac{1}{1+e^{-K \cdot s}}
$$

where $\mathrm{K}$ is the slope parameter of the sigmoid function.

\subsection{Training algorithm}

Training or learning is the method of modifying the parameters (e.g. the weights) of the neural network in order to reach a desired goal. We can somehow classify learning with respect to the learning mechanism, with respect to when this modification takes place, and according to the manner how the adjustment takes place. In this paper the artificial neural network is trained in supervised, off-line manner by bacterial memetic algorithm [3].

Nature inspired evolutionary optimization algorithms are often suitable for global optimization of even nonlinear, high-dimensional, multi-modal, and discontinuous problems. Bacterial Evolutionary Algorithm (BEA) [9] is one of these techniques. BEA uses two operators, the bacterial mutation and the gene transfer operation. These operators are based on the microbial evolution phenomenon. The bacterial mutation operation optimizes the chromosome of one bacterium, the gene transfer operation allows the transfer of information between the bacteria in the population.

Evolutionary algorithms are global searchers, however in most cases they give only a quasi-optimal solution to the problem, because their convergence speed is low. Local search approaches can give a more accurate solution, however they are searching for the solution only in the neighborhood of the search space. Local search approaches might be useful in improving the performance of the basic evolutionary algorithm, which may find the global optimum with sufficient precision in this combined way. Combinations of evolutionary and localsearch methods are usually referred to as memetic algorithms [8].

In the following an already completed research is presented. This particular research consisted of the prediction of warehouse performance however we could use its methodology for production control also.

\subsection{Use of ANN for warehouse performance measurement}

The participant of this project was a central warehouse of a global company acting also as a distribution center for Central Europe and as a finished goods warehouse for the Hungarian factory. An additional task of the warehouse is to serve other warehouses with full truck loads. This makes the warehouse a true logistic service provider 
despite that it is situated beside a factory. This status comes with additional challenges and problems like the following:

- Different performance factors at outbound flows regarding directions

- Different requirements for the different outgoing flows.

These facts had serious effects on performance measurement that is to be discussed later.

The warehouse itself has $25.000 \mathrm{~m} 2$ surface. It has 25 ramps 53 gates. 7 gates are used for outgoing traffic.

The storing technology includes two major storing technologies:

- $\quad$ Shelves with 4 levels

- Block storage

The block storage is used mainly for the factory products.

Other important task of the warehouse is the distribution and collection of pallets within the whole company supply chain.

At the warehouse the strategic level performance measurement is based on various Balanced Scorecard (BSC) based results such as damaged goods, customer complaints, inventory differences among others. Our goal was to develop a tool that is able to create a direct connection between those indicators and various operational level indicators such as incoming goods, delivered goods, transhipment, and placement within the warehouse, capacity usage of the warehouse and overtime of the workers.

As described before the connection between the above mentioned indicators is very complex and inter-related. Simple calculations and regression analysis was not able to model the inter-relations and complexity of the various input parameters and so the prediction of strategic level performance indicators based on operational level actions was inaccurate.

The major problem with this performance measurement system was that it relied on the pre-defined norms. If the performance is high for a given amount of time the management will raise the norm values. However, if the complexity of the tasks is raising the norm values will not be lowered. This one-direction inelasticity can make the operative feedback about performance inaccurate.

The main idea behind the use of the proposed model was that we needed a link between complex Balance Scorecard indicators and easy-to-measure and easy-toobtain indicators. After visiting the warehouse, we found that the operating SAP-based business software is frequently used to obtain operational level data and is capable to obtain other data not used yet. Based on the above information our first task was to obtain a logical link between some of the already available data and a BSC indicator.

For the pilot test we have chosen the warehouse efficiency Key Performance Indicator (KPI). In the next step we identified operational level data that is most likely being in logical connection with this indicator.

We have chosen the following operational level data and with the help of the warehouse staff we received the required number of them:
- Percentage of not full pallets among outgoing goods

- Work load (actual/norm)

- Warehouse storage capacity utilization (in $\mathrm{m}^{3}$ and in percentage)

With the exact logical connection described and with the use of hypothetical or forecasted operational level data the approximate value of the KPI could be calculated. For this purpose, we used the aforementioned artificial neural network. After the learning and testing phase the program was able to calculate the number of damaged goods used the aforementioned operational level indicators as input.

\subsection{Results and evaluation of the example}

In the experiments we performed 10 simulations using 7 hidden neurons and the mean relative error (MRE) of the train and test set was investigated which is defined as:

$$
M R E=\frac{1}{p} \sum_{i=1}^{p}\left|\frac{y_{i}-t_{i}}{y_{i}}\right|
$$

where $y_{i}$ is the output of the network for the $i$-th pattern, $t_{i}$ is the desired output for the $i$-th pattern, and $p$ is the number of patterns.

Table 1 shows the best, the average, and the worst results based on the 10 simulations.

Table 1. Experimental results.

\begin{tabular}{l|cl}
\hline & Train & Test \\
\hline \multirow{2}{*}{ Average } & $15.82 \%$ & $\begin{array}{l}17.42 \\
\%\end{array}$ \\
& & 17.17 \\
Best & $15.56 \%$ & $\%$ \\
& & 17.61 \\
Worse & $16.01 \%$ & $\%$ \\
\hline
\end{tabular}

In our previous papers [12], [13] we presented one possible use of this model. In that case the strategic level indicator was the percentage of damaged goods at the warehouse. This model was further developed with the evaluation feature.

For further testing and to promote the further possibilities of the ANN we prepared five scenarios based on the test (Fig. 2).

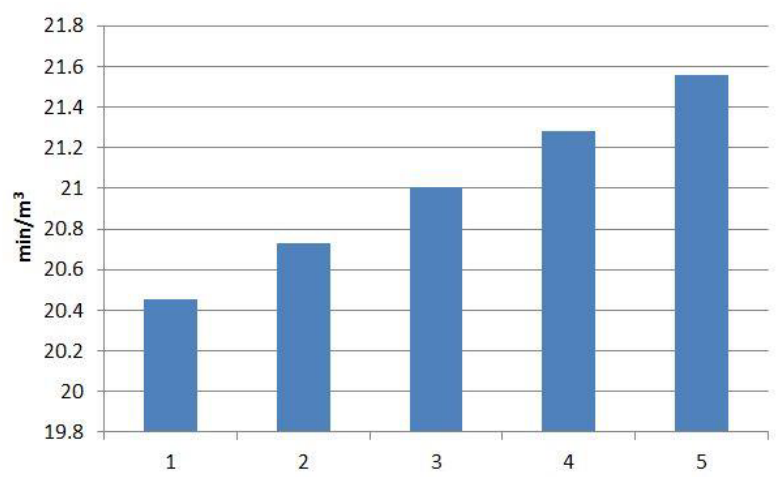

Figure 2. Evaluation of the scenarios.

The first scenario describes a best-case scenario. The warehouse storage capacity utilization is at a low level; 
with lowered percentage for the not full pallets and low workload.

The fifth scenario is a worst-case scenario, the warehouse storage capacity utilization at a high level, high work load and large percentage for not full pallets.

For further evaluation of the model we created more scenarios leaving all but one input unchanged. The results showed that "ceteris paribus" - leaving all other inputs un- changed - a rise in the workload level affect the warehouse productivity the most (Fig. 3). By this way we can eliminate all inputs that are not relevant enough for the model. After that - besides the aforementioned parameter - we can insert new inputs for a repeated learning of the ANN. That will further improve the model and help to find all operational level data that matters the most for the warehouse efficiency.

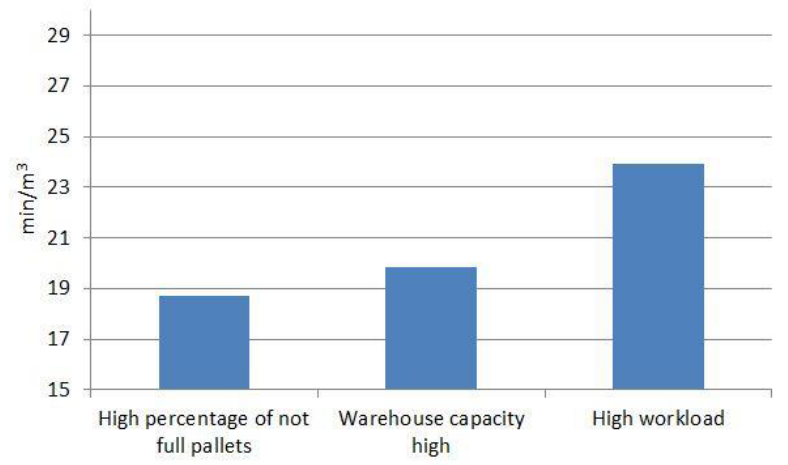

Figure 3. Evaluation of results

\section{Adapting research method to production control}

The aforementioned method can be used for the production control in small batch production. Our aim is to use it first for the prediction of the production planning accuracy. This accuracy is one of the most important factors in small batch manufacturing. If this accuracy is high enough the production can fulfil the orders in the given time window and can achieve competitive advantage in the long run.

As an input the following data will be used:

- Production quantity

- Production complexity (number of assembly steps)

- Capacity utilization

With enough data of previous production shifts together with the measured accuracy of production planning - we will be able to simulate this output value with changing the input data according to the production plan. This could be used as a decision making tool: By given number of orders (production quantity and complexity) the adjusting of capacity utilization - by adjusting maintenance time for example - can increase the accuracy of production planning. Or, the other way around, by given maintenance time or pre-defined capacity utilization the number of orders will give the predicted accuracy thus helping the production control with possible output of the current shift - even before production started.

We are currently in the stage of collecting enough data. The results will be presented in later papers.

\section{Conclusions}

We can state that the proposed method can be adapted to production control. With enough data collected we can create a decision making tool for production logistics decision makers. As stated before, the collection of data started already and first test of the method is planned for the second half of 2016 .

\section{Acknowledgement}

This work was supported by OTKA Fund (K-105529) of the Government of Hungary.

\section{References}

1. Ko M, Tiwari A, Mehnen J, “A review of soft computing applications in supply chain management" Applied Soft Computing, 10, (2010), pp. 661-674

2. Botzheim J, Földesi P, "Fuzzy neural network with novel computation of fuzzy exponent in the sigmoid functions." In: Proceedings of the 8th International Symposium on Management Engineering, ISME 2011, Taipei, Taiwan, pp. 285-291

3. Botzheim J, Cabrita C, Kóczy LT, Ruano AE, "Fuzzy rule extraction by bacterial memetic algorithms." In: Proceedings of the 11th World Congress of International Fuzzy Systems Association, IFSA 2005, Beijing, China, pp. 1563-1568

4. Bozarth CC, Warsing DP, Flynn BB, Flynn EJ, "The impact of supply chain complexity on manufacturing plant performance." Journal of Operations Management 27(1) (2009), pp. 78-93

5. Dubois A, Hulthén K, Pedersen AC "Supply chains and interdependence: a theoretical analysis." Journal of Purchasing and Supply Management 10(1) (2004), pp. 3-9

6. Gál L, Botzheim J, Kóczy LT, Ruano AE, “Applying bacterial memetic algorithm for training feedforward and fuzzy flip-flop based neural networks." In: Proceedings of the 2009 IFSA World Congress and 2009 EUSFLAT Conference, IFSA-EUSFLAT 2009, Lisbon, Portugal, pp. 1833-1838

7. Hecht-Nielsen R, Neurocomputing. Addison-Wesley (1990)

8. Moscato P, "On evolution, search, optimization, genetic algorithms and martial arts: Towards memetic algorithms.” Tech. Rep. Caltech Concurrent Computation Program, Report. 826, (1989) California Institute of Technology, Pasadena, California, USA

9. Nawa NE, Furuhashi T: "Fuzzy system parameters discovery by bacterial evolutionary algorithm." IEEE Transactions on Fuzzy Systems 7(5) (1999), pp. 608616

10. Németh P, "Flexibility in supply chains" Acta Technica Jaurinensis Series Logistica, 1(2) (2008) pp.371-379.

11. Németh $P$, “Ellátási láncok hatékony irányítása multi kritériumos teljesítmény méréssel” (in Hungarian). 
Ph.D. thesis, 2009, Széchenyi István University, Győr, Hungary

12. Németh P, Földesi P, Botzheim J, "Enhancing warehouse performance at a global company" In: Proceedings of Knowledge Globalization Conference, Boston, Massachusetts, (October 2011), pp. 7-19.

13. Németh P, Földesi P, Csík Á, "The concept of logistic space in the modelling of supply chain performance" In: Proceedings of the 22nd Annual
Production and Operations Management Society Conference, Reno, Nevada, (May 2011)

14. Zurada JM, Introduction to Artificial Neural Systems, West Publishing Co., St. Paul (1992)

15. Bhagwat R, Sharma MK, "Performance measurement of supply chain management: A balanced scorecard approach", Computers \& Industrial Engineering 53(1) (2007) pp. 43-62 